\title{
Research Article \\ Study on Carbonyl Emissions of Diesel Engine Fueled with Biodiesel
}

\author{
Ruina Li, ${ }^{1}$ Zhong Wang, ${ }^{1}$ and Guangju $\mathrm{Xu}^{2}$ \\ ${ }^{1}$ School of Automobile and Traffic Engineer, Jiangsu University, Zhenjiang 212013, China \\ ${ }^{2}$ Changshu Institute of Technology, Suzhou 215500, China
}

Correspondence should be addressed to Ruina Li; liruina0706@126.com

Received 30 November 2016; Revised 24 January 2017; Accepted 13 February 2017; Published 20 March 2017

Academic Editor: Sankar Chakma

Copyright (c) 2017 Ruina Li et al. This is an open access article distributed under the Creative Commons Attribution License, which permits unrestricted use, distribution, and reproduction in any medium, provided the original work is properly cited.

\begin{abstract}
Biodiesel is a kind of high-quality alternative fuel of diesel engine. In this study, biodiesel and biodiesel/diesel blend were used in a single cylinder diesel engine to study the carbonyl emissions. The result shows that carbonyl pollutants of biodiesel and biodiesel/diesel blend are mainly aldehyde and ketone compounds with 1-3 carbon atoms, and formaldehyde concentration is higher than $80 \%$ of the total carbonyl pollutants for biodiesel. The formaldehyde concentration peak is reduced with the increase of intake temperature $(T)$, intake pressure $(P)$, and exhaust gas recirculation (EGR) ratio and increased with the increase of compression ratio $(\varepsilon)$. When excess air coefficient $(\lambda)$ is lower than 1.7 , the formaldehyde concentration is increased with the increase of excess air ratio. When $\lambda$ is higher than 1.7, the formaldehyde concentration is reduced with the increase of excess air ratio. The dilution of air can reduce formaldehyde concentration in the premixed flame of diesel effectively; however, it has less effect on biodiesel. Among the fuel pretreatment measures of adding hydrogen, $\mathrm{CO}$, and methane, the addition of hydrogen shows the best effect on reducing formaldehyde of biodiesel.
\end{abstract}

\section{Introduction}

Biodiesel which is mainly made from animal oils, vegetable oils, or waste cooking oils by esterification reaction is a kind of clean renewable energy. Studies $[1,2]$ show that biodiesel could be used in diesel engine without any modification. And by now, biodiesel has been got widespread attention and becomes an important alternative fuel of diesel engine [3-5]. In China, the government has paid much attention on biodiesel these years. Both BD100 and B5 standards were promulgated in 2007 and 2010 in China, and these standards have opened the door for biodiesel to enter the oil market.

Due to the extensive sources of biodiesel and residual alcohols, acids, alkalis, and other impurities in the preparation process of biodiesel, the THC of diesel engine fueled with biodiesel includes the unburned hydrocarbon, alkanes, alkenes, and carbonyl emissions. Among these THC, carbonyl compounds are the intermediate oxidation products of the fuel. Carbonyl compounds which have high chemical activity and genetic toxicity are easy to cause the DNA chain cross-linking and DNA fracture. Carbonyl compounds can stimulate human respiratory tract and cause inflammation of respiratory tract, nervous system dysfunction, and other diseases. Short-term inhalation of carbonyl compounds may cause irritation to human's eyes, skin, and mucous membranes of the nasal cavity. However, long time in the environment of a low concentration of carbonyl compounds, carbonyl compounds may be toxic to human respiratory system, nervous system, and immune system and even will cause cancer $[6,7]$. At present, carbonyl emissions have attracted much attention of environmental protection departments in many countries and organizations. For example, formaldehyde is identified as a strong teratogenic and carcinogenic substance by WHO [8]. In China, formaldehyde is in the second place of the priority controlled toxic chemicals. In the New Clean Air Act of America, 9 kinds of aldehydes and ketones are taken as the important pollutants need to be controlled. Researchers have also carried out studies on carbonyl emissions of diesel engine. Yuan et al. [9] studied carbonyl emissions in a heavy-duty diesel engine fueled with biodiesel/diesel blend. The result shows that formaldehyde 
is the major carbonyl emissions in the carbonyl emissions, accounting for 70.1-76.2\%. The addition of biodiesel in diesel can reduce formaldehyde emission. Chai et al. [10] tested the carbonyl compounds of B50 and B100 in a nonroad diesel generator. The result shows that formaldehyde, acetaldehyde, and acrolein are the most abundant carbonyl compounds emitted for both diesel and biodiesel. He et al. [11] investigated carbonyl compounds emissions of biodiesel on a direct injection, turbocharged diesel engine. The experimental result indicates that biodiesel-fueled engine almost has triple carbonyls emissions of diesel-fueled engine, and formaldehyde is the most abundant compound of carbonyls for both biodiesel and diesel, taking part for $46.2 \%$ and $62.7 \%$, respectively. Ballesteros et al. [12] studied the carbonyl pollutants of biodiesel/diesel blend in a 4-cylinder diesel engine. The result shows that the addition of biodiesel in diesel increases carbonyl emissions. However, the trend was occasionally different if the emissions were studied after the DOC. Zhang et al.'s [13] study on regulated and unregulated emissions of diesel engine fueled with diesel and fumigation methanol shows that the NOx emission is about more than 40 times higher than formaldehyde emission, and the posttreatment of DOC can reduce the formaldehyde emission. Though the emission amount of carbonyl pollutants of diesel fuel is not as much as regulated pollutants, the harm of carbonyl pollutants to human health may be more serious than regulated pollutants. It is meaningful to carry out studies on carbonyl emissions of diesel engine, getting a better understanding on carbonyl pollutants' formation process and putting forward better control measures of carbonyl emissions.

In this paper, an engine bench test was carried out on 186FA diesel engine fueled with biodiesel and biodiesel/diesel blend. The carbonyl emissions were collected at different working condition and measured by solvent extraction and HPLC technology. The relationship of 13 kinds of carbonyl pollutants with engine loads was analyzed. In CHEMKIN simulation, $\mathrm{n}$-heptane and methyl decanoate mechanisms are taken as the alternative mechanisms of diesel and biodiesel respectively. The effects of $T, P, \varepsilon, \lambda$, and EGR ratio on formaldehyde concentration were simulated with HCCI condition. At last, two pretreatment measures to reduce formaldehyde were put forward and analyzed in the premixed flame of biodiesel.

\section{Measurement of Carbonyl Emissions}

2.1. The Fuel Preparation and Test Scheme. The diesel used in the test was commercially available $0^{\#}$ diesel, and the biodiesel was provided by KATA NEW ENERGY in Changzhou, China. And properties of the diesel and biodiesel were listed in Table 1. In the blend fuel, biodiesel was blended in diesel with the volume ratio of $0 \%, 50 \%$, and $100 \%$, and they were named as BD0, BD50, and BD100, respectively.

The test was carried out on 186FA diesel engine. The engine specifications of 186FA are listed in Table 2. The experiment was conducted at $3600 \mathrm{rpm}$ and the BMEP was $0.05 \mathrm{MPa}, 0.13 \mathrm{MPa}, 0.25 \mathrm{MPa}, 0.38 \mathrm{MPa}$, and $0.50 \mathrm{MPa}$, respectively. The injection timing and fuel injection quantity
TABLE 1: Physical and chemical properties of biodiesel and diesel.

\begin{tabular}{lcc}
\hline Fuel & Biodiesel & $0^{\#}$ diesel \\
\hline Density $\left(\mathrm{kg} / \mathrm{m}^{3}\right)$ & 881 & $825 \sim 840$ \\
Viscosity $\left(\mathrm{mm}^{2} / \mathrm{s}\right)$ & 4.47 & $3.0 \sim 8.0$ \\
Cetane number & 51.2 & $\geq 49$ \\
Low calorific value $(\mathrm{MJ} / \mathrm{kg})$ & 33.6 & 42.5 \\
Carbon hydrogen ratio & 8.73 & 6.56 \\
Oxygen content $(\%)$ & 13.5 & 0 \\
Self-ignition temperature $(\mathrm{K})$ & 628.5 & $473 \sim 493$ \\
\hline
\end{tabular}

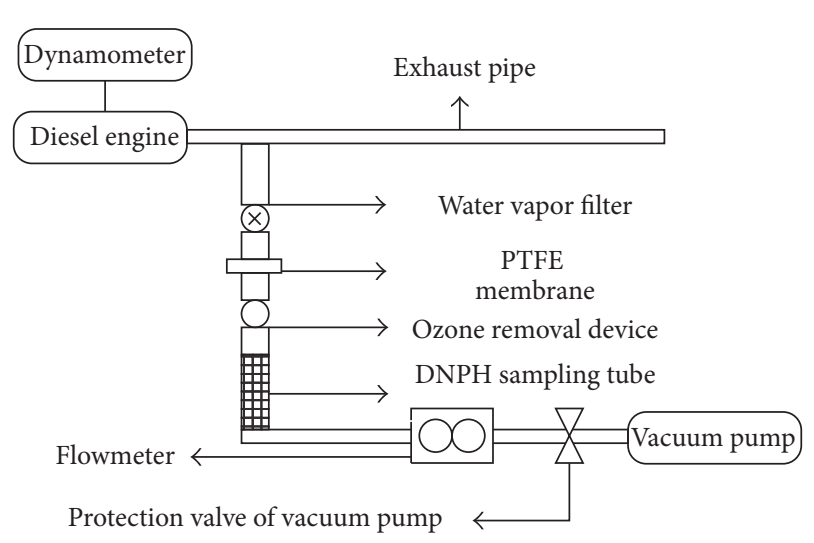

FIGURE 1: Diagram of sample collection apparatus.

of the engine were unchanged. In this test, the blend fuel mentioned above was used in the engine operation.

2.2. Sampling Collection and Processing. Figure 1 is a schematic diagram of the sampling system. The main sampling devices are listed as follows: miniature vacuum pump (VAA5008-24V), flowmeter (LZB-6WB), particulate filters, regulated power supply, DNPH sampling tubes, ozone washing tubes, and vapor filter. The sample pretreatment devices are ultrasonic extractor, rotary evaporator, and sample bottles. In the sample collection procedure, exhaust runs through the vapor filter, particulate filter, ozone washing tube, DNPH sampling tube, flow meter, and vacuum pump in sequence. In order to eliminate the interference of water vapor, particulate matter, and ozone in the exhaust gas, the sampling flow rate is maintained at $2 \mathrm{~L}$ per min by the control of the vacuum pump. To prevent the penetration phenomenon, the sampling time is set as 10 minutes. After sampling, the two sampling tubes at the end were sealed with Teflon caps to avoid light and cold storage. Then transfer the sample to a clean volumetric flask, and add a certain amount of acetonitrile. After ultrasonic extraction and concentration to $1 \mathrm{ml}$, keep in cold storage and avoid light. As the vacuum pump was used during the sampling collection process, the sampling collection will not create any back pressure on the engine.

As derivatization and HPLC have the advantage of high sensitivity, strong selectivity, and good reproducibility, in this test, derivatization and HPLC were used to test the carbonyl pollutants of diesel engine. Detection and analysis devices are HPLC-UV detector, C18 column. Reagents are methanol 
TABLE 2: Engine specification of 186FA.

\begin{tabular}{ll}
\hline Type & Direct-injected, 4 stokes, air-cooled, natural aspiration \\
\hline Number of cylinders & 1 \\
Cylinder bore $(\mathrm{mm}) \times$ stroke $(\mathrm{mm})$ & $86 \times 72$ \\
Displacement $(\mathrm{L})$ & 0.418 \\
Compression ratio & 19 \\
Rated power $(\mathrm{kW}) /$ speed $(\mathrm{r} / \mathrm{min})$ & $6.3 / 3600$ \\
Nozzle number $\times$ orifice diameter $(\mathrm{mm})$ & $5 \times 0.20$ \\
Injection advanced angle $\left({ }^{\circ} \mathrm{CA}\right.$ BTDC) & 12 \\
Combustion chamber & $\omega$ type \\
\hline
\end{tabular}

TABLE 3: The retention time and resolution of Agilent-C18 columns.

\begin{tabular}{lcc}
\hline Carbonyl compounds & Retention time/min & Resolution \\
\hline Formaldehyde-DNPH & 3.454 & 1.850261 \\
Acetaldehyde-DNPH & 4.066 & 1.935543 \\
Propylene aldehyde-DNPH & 4.474 & 3.459658 \\
Acetone-DNPH & 5.892 & 1.032619 \\
Propionaldehyde-DNPH & 6.651 & 1.932641 \\
Crotonaldehyde-DNPH & 8.307 & 3.995684 \\
Butanone-DNPH & 10.703 & 1.954623 \\
Butyraldehyde-DNPH & 10.925 & 0.896578 \\
Benzene formaldehyde-DNPH & 11.358 & 0.379284 \\
Isovaleraldehyde-DNPH & 12.294 & 2.759839 \\
\hline
\end{tabular}

(AR level), acetonitrile (HPLC level), and deionized water which will reduce conversion of carbonyl pollutants during the sampling collect and standard mixture of 13 carbonyl components.

UV detectors are commonly used in liquid chromatography. DNPH is a derivatization reagent with UV-absorbing group. Carbonyl compounds can react with DNPH; then the reaction product will get a chromophoric group which can be detected. The minimum detectable amount of UV detector for such derivatized product was $5 \mathrm{ng}$.

Two adsorption columns were used to measure the absorption efficiency and the penetration effect of the sampling column. The sampling rate and sampling time were determined. A sample was eluted with acetonitrile for 2 times, and the elution efficiency was determined.

\subsection{Sample Measurement Accuracy Analysis}

\subsubsection{Selection of Chromatographic Column and Detection} Wavelength. To separate and test the 13 carbonyl compounds in diesel engine exhaust in gradient elution conditions, the Agilent-C18 reversed-phase high performance liquid chromatography column was used, and acetonitrile/water was the mobile phase. Due to the fact that the retention time of butanone and butyraldehyde is similar, it is not easy to separate these two compounds. Butanone and butyraldehyde were as one detection target. Table 3 displays the retention time and resolution of carbonyl compounds on Agilent-C18 column. It can be seen that the detection goal has a reasonable retention time and a better resolution.
Saturated aldehyde hydrazones of DNPH have strong absorption at $360 \mathrm{~nm}$ [14], so the detection wavelength of UV detector was set at $360 \mathrm{~nm}$.

2.3.2. Standard Curve and Linear Range. In the research work, 13 kinds of aldehyde and ketone samples were diluted with acetonitrile in accordance with the ratio of 100, 50, 20, 10 , and 3 times, respectively. Then $10 \mu \mathrm{l}$ solution was used to chromatography test. After the linear regression analysis of concentration and peak area, the curve equation was obtained. The results were shown in Table 4 . It can be seen that $R^{2}$ of the standard curve at the maximum absorption wavelength for 13 kinds of aldehyde and ketone were all more than 0.99 , and the linear range was $0.8 \sim 35000 \mu \mathrm{g} \mathrm{L}^{-1}$. The good linearity and wide linear range could achieve the accurate determination of carbonyl compounds.

2.3.3. Accuracy. In accuracy test, acetonitrile was used to dilute standard sample solution of aldehyde or ketone 2000 times. And the samples were tested 6 times under the same conditions. Then $X$ and RSD were calculated. The calculation results were shown in Table 4 . It can be seen that the RSD of carbonyl compounds was $1.03 \% \sim 0.09 \%$, which meant high measurement accuracy.

2.4. Result and Discussion. The formaldehyde and acetaldehyde mass concentration for diesel engine fueled with BD0, BD50, and BD100 was shown in Figures 2(a) and 2(b). As can be seen, the formaldehyde concentration of BD0 and BD50 is increased with the increase of engine load, 
TABLE 4: The linear equation, correlation coefficient, and linear range of the 13 kinds of hydrazones.

\begin{tabular}{|c|c|c|c|c|c|c|}
\hline Number & Carbonyl compounds & Linear equation & Correlation coefficient $R^{2}$ & Linear range $/ \mu \mathrm{g} \cdot \mathrm{L}^{-1}$ & $X \mu \mathrm{g} \cdot \mathrm{L}^{-1}$ & RSD $\%$ \\
\hline (1) & Formaldehyde-DNPH & $y=20.961 x+40.301$ & 0.998 & $2.1 \sim 35000$ & 2231 & 0.21 \\
\hline (2) & Acetaldehyde-DNPH & $y=20.965 x+29.204$ & 0.998 & $1.5 \sim 25500$ & 1154 & 0.09 \\
\hline (3) & Propylene aldehyde-DNPH & $y=20.596 x+19.956$ & 0.999 & $1.3 \sim 21100$ & 1198 & 0.45 \\
\hline (4) & Acetone-DNPH & $y=21.883 x+30.405$ & 0.998 & $1.2 \sim 20500$ & 1069 & 1.02 \\
\hline (5) & Propionaldehyde-DNPH & $y=20.656 x+23.4$ & 0.999 & $1.2 \sim 20500$ & 1109 & 0.38 \\
\hline (6) & Crotonaldehyde-DNPH & $y=19.527 x+19.294$ & 0.998 & $1.1 \sim 17900$ & 1203 & 0.86 \\
\hline (7) & Butyraldehyde-DNPH & $y=19.33 x+13.8$ & 0.998 & $1.1 \sim 17500$ & 1195 & 0.97 \\
\hline (8) & Butanone-DNPH & $y=18.294 x+12.02$ & 0.999 & $0.8 \sim 13500$ & 1086 & 0.58 \\
\hline (9) & Benzene formaldehyde-DNPH & $y=16.01 x+6.7033$ & 0.999 & $0.8 \sim 12500$ & 1097 & 0.36 \\
\hline$(10)$ & Isovaleraldehyde-DNPH & $y=19.229 x+7.4782$ & 0.998 & $0.9 \sim 15500$ & 1065 & 0.42 \\
\hline (11) & n-Valeraldehyde-DNPH & $y=18.99 x+10.123$ & 0.998 & $0.9 \sim 15500$ & 1124 & 0.68 \\
\hline$(12)$ & Hexaldehyde-DNPH & $y=18.34 x+5.9823$ & 0.996 & $0.8 \sim 13900$ & 1171 & 0.56 \\
\hline (13) & Two-methyl phenyl formaldehyde-DNPH & $y=17.678 x+7.3944$ & 0.999 & $0.8 \sim 11700$ & 1132 & 1.03 \\
\hline
\end{tabular}

while the formaldehyde concentration of BD100 is increased first and then reduced. There is little difference between the formaldehyde concentration of BD100 and BD50 at $0.05 \mathrm{MPa}$, both about $12 \mathrm{mg} / \mathrm{m}^{3}$, while formaldehyde mass concentration of BD0 is higher, about $18 \mathrm{mg} / \mathrm{m}^{3}$. When diesel engine is operated at $0.50 \mathrm{MPa}$, formaldehyde mass concentration of $\mathrm{BD} 100$ is about $13 \mathrm{mg} / \mathrm{m}^{3}$, much lower than that of BD0 and BD50, about $29 \mathrm{mg} / \mathrm{m}^{3}$. With the increase of engine load, acetaldehyde mass concentrations for the blend with different blending ratios are all reduced. Acetaldehyde mass concentration of BD50 and BD100 has a sudden rise at $0.13 \mathrm{MPa}$. When at low load, acetaldehyde mass concentration of $\mathrm{BD} 100$ is the highest.

The acrolein and acetone mass concentration of diesel engine fueled with BD0, BD50, and BD100 was shown in Figures 2(c) and 2(d). As can be seen, the acrolein concentration of BD100 is lower than that of BD0 and BD50 in the entire load range. The difference between acrolein concentration of BD50 and BD100 at the low and medium load is not obvious, and the acrolein concentration of BD0 is the highest at high load. With the increase of engine load, acetone concentrations of the blend with different blending ratios are all increased first and then reduced. The acetone concentration of BD100 is the highest at low and medium load. When at high load, acetone concentration of BD100 is decreased rapidly to $0.02 \mathrm{mg} / \mathrm{m}^{3}$, while acetone concentration of acetone concentration of $\mathrm{BD} 0$ is the highest, about $0.18 \mathrm{mg} / \mathrm{m}^{3}$.

Figures 2(e) and 2(f) show propionaldehyde and crotonaldehyde concentration of diesel engine fueled with BD0, $\mathrm{BD} 50$, and BD100. It can be seen that the propionaldehyde concentration of BD0 is the highest within the entire load range. When at low and medium load, the acrolein concentration of BD50 and BD100 are almost the same, about $1.0 \mathrm{mg} / \mathrm{m}^{3}$, and there is little difference among crotonaldehyde concentration of BD0, BD50, and BD100 at $0.25 \mathrm{MPa}$. The crotonaldehyde concentration of $\mathrm{BD} 0$ and $\mathrm{BD} 50$ is increased at high load, and the crotonaldehyde concentration of BD100 is the lowest within the entire load range.
Figures 2(g) and 2(h) show butanone/butyraldehyde and benzaldehyde concentration of diesel engine fueled with BD0, BD50, and BD100. As can be seen, the butanone/ butyraldehyde concentration of BD50 and BD100 is increased with the increase of engine load. And the butanone/butyraldehyde concentration of BD100 is lower than that of BD0 and BD50, especially at high load. At $0.50 \mathrm{MPa}$, the butanone/butyraldehyde concentration of BD0 is the highest, about $1.1 \mathrm{mg} / \mathrm{m}^{3}$. The benzaldehyde concentration of BD0 is the highest within the entire load, and no benzaldehyde of BD100 is detected in the exhaust gas at $0.05 \mathrm{MPa}$.

Figures 2(i) and 2(j) show isovaleraldehyde and valeraldehyde concentration of diesel engine fueled with BD0, $\mathrm{BD} 50$, and BD100. It can be seen that there is little difference on isovaleraldehyde concentrations between of BD0 and $\mathrm{BD} 50$ in the entire engine load, much lower than that of BD0. No isovaleraldehyde is detected for BD100 at $0.05 \mathrm{MPa}$, $0.38 \mathrm{MPa}$, and $0.50 \mathrm{MPa}$. With the increase of engine load, the valeraldehyde concentration of BD100 is increased first and then reduced.

Figures 2(k) and 2(l) show hexanal and two-methyl benzaldehyde concentration of diesel engine fueled with $\mathrm{BD} 0, \mathrm{BD} 50$, and BD100. It can be seen that no hexanal was detected for BD50 at low and medium load and BD100 at high load. The hexanal concentration of BD0 is increased with the increase of engine load. The two-methyl benzaldehyde concentration of BD100 is lower than BD0 and BD50.

Figure 3 is the total carbonyl pollutants of diesel engine fueled with the fuels. As can be seen, at low and medium load, the total carbonyl emissions for BD0 and BD50 are almost the same, both about $20 \mathrm{mg} / \mathrm{m}^{3}$. The total carbonyl emissions for BD0 and BD50 are increased with the increase of engine load. At high load, the total carbonyl emissions for BD0 are the highest and followed by BD50 and BD100.

The analysis above indicates that carbonyl emissions of diesel engine fueled with BD0, BD50, and BD100 are mainly aldehyde and ketone compounds with 1-3 carbon atoms, such as formaldehyde, acetaldehyde, acrolein, and 


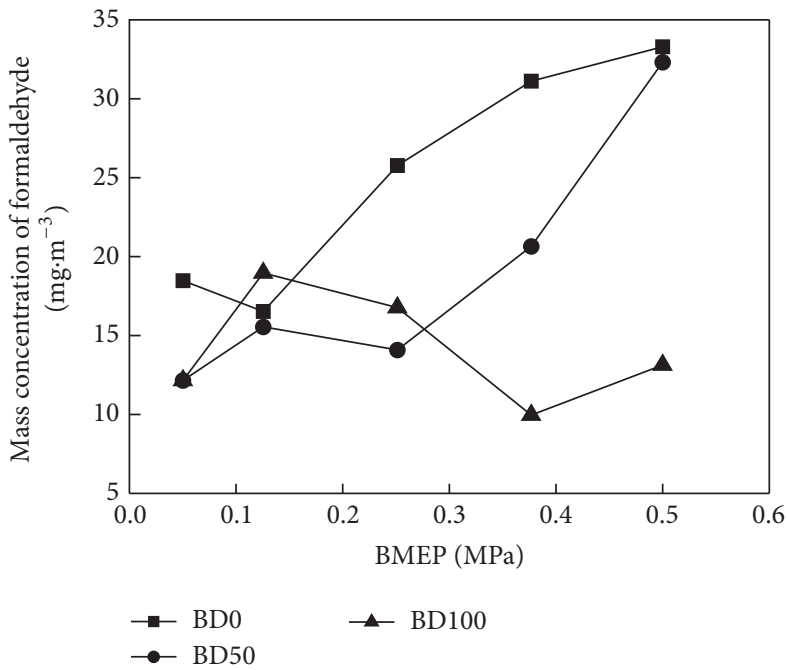

(a) Formaldehyde

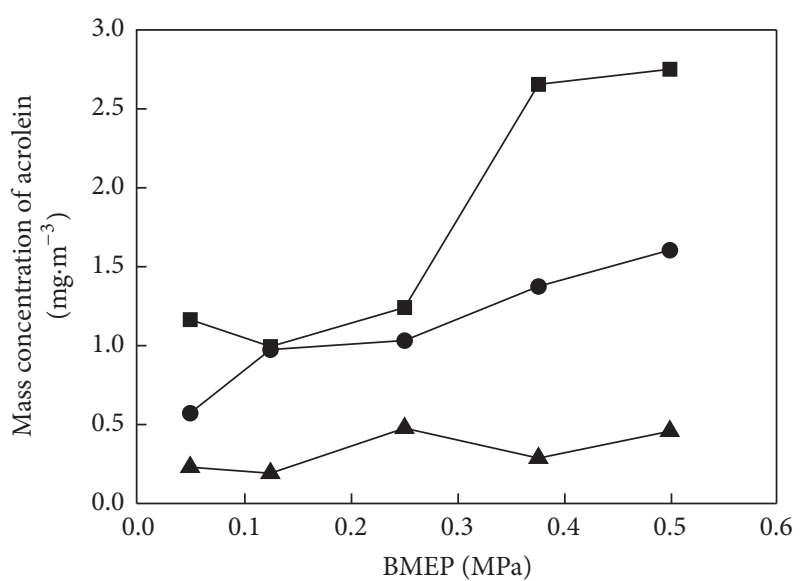

$$
\rightarrow \text { BD0 }
$$$$
\rightarrow \text { BD50 }
$$

(c) Acrolein

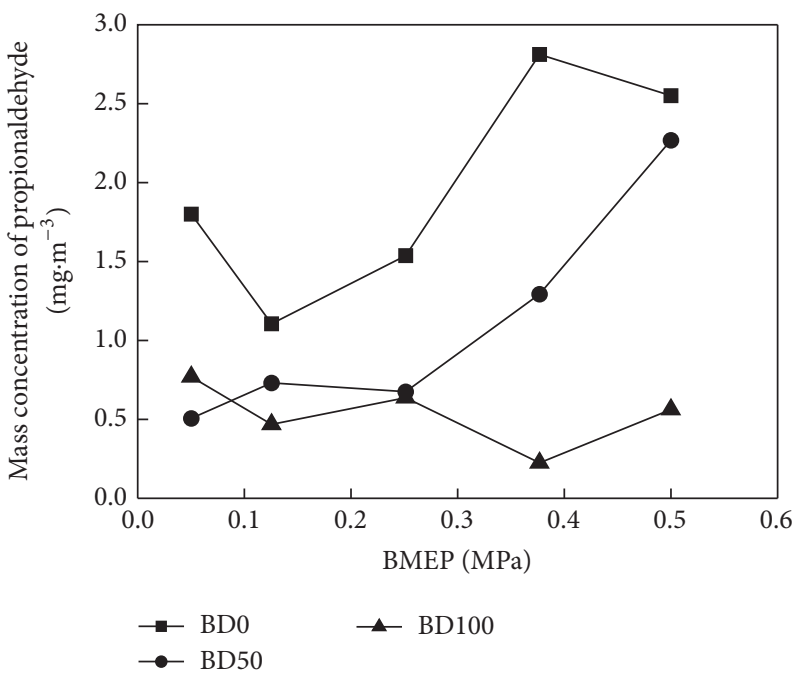

(e) Propionaldehyde

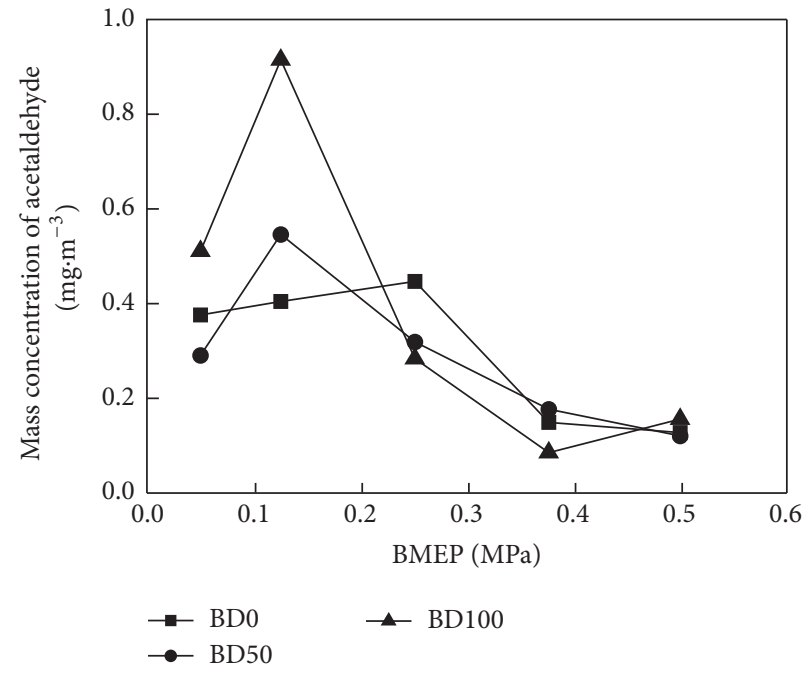

(b) Acetaldehyde

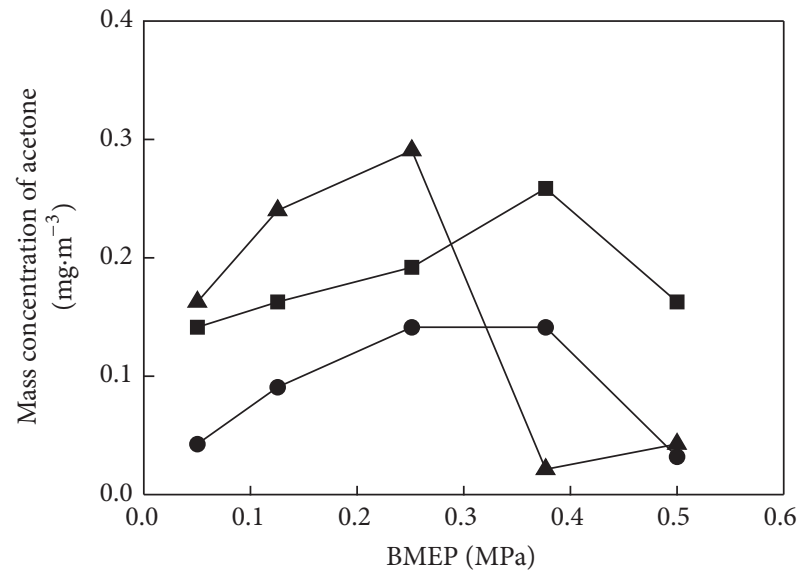

$\rightarrow-\mathrm{BD} 0$

$\_\mathrm{BD} 100$

(d) Acetone

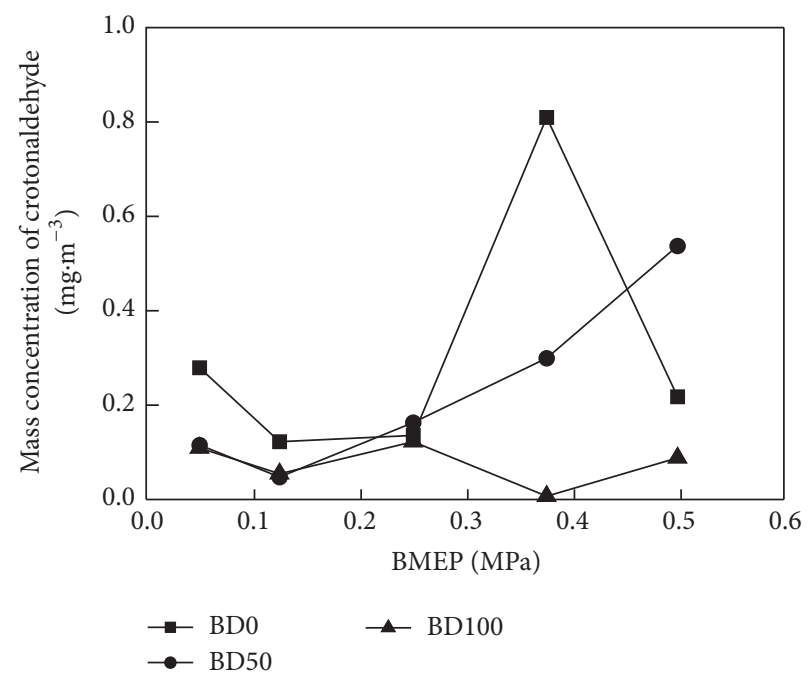

(f) Crotonaldehyde

Figure 2: Continued. 

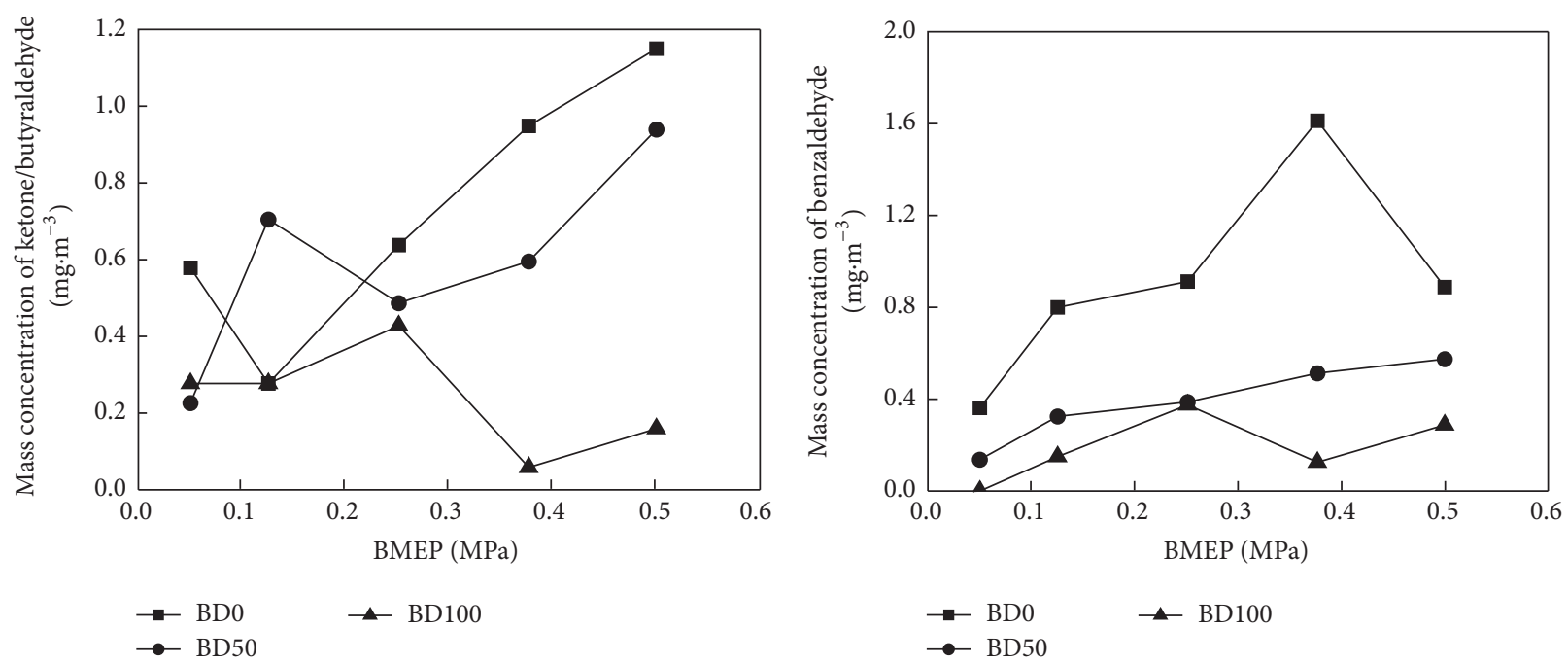

(g) Ketone/butyraldehyde
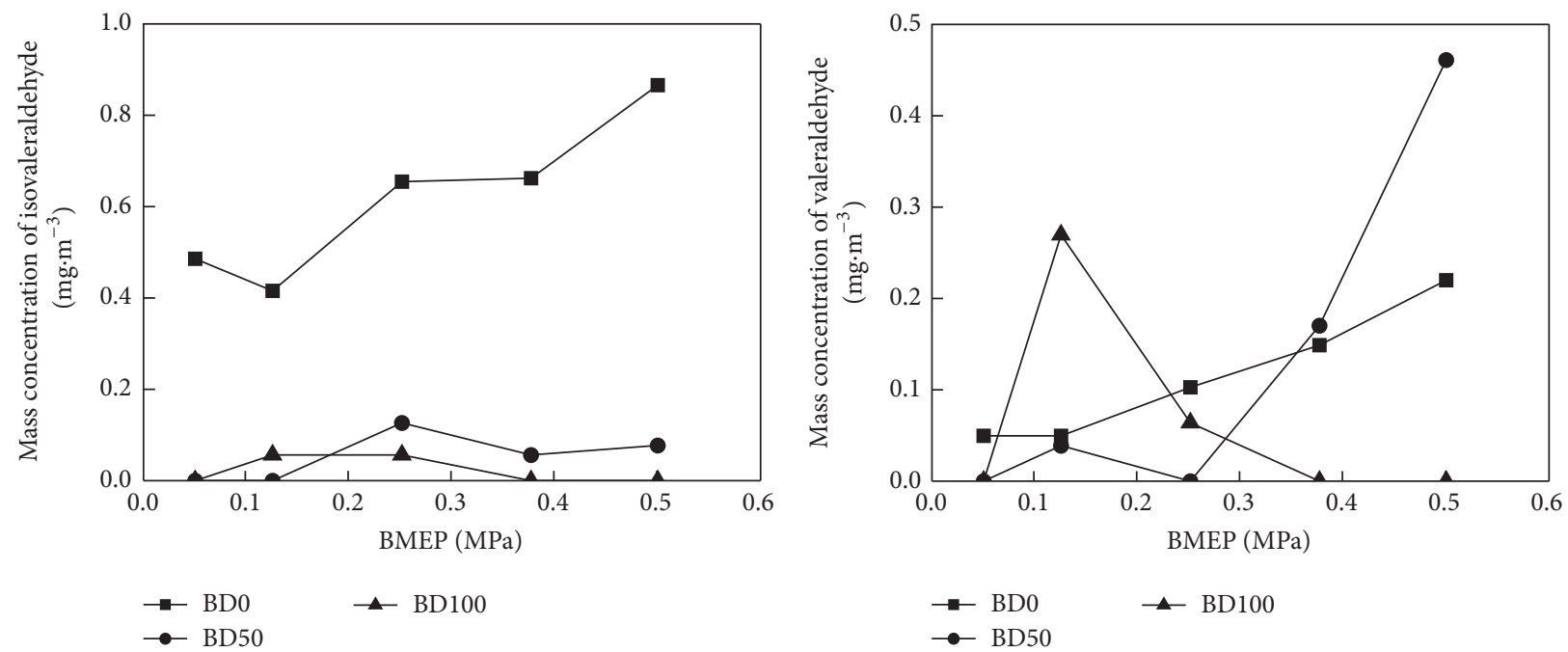

(i) Isovaleraldehyde
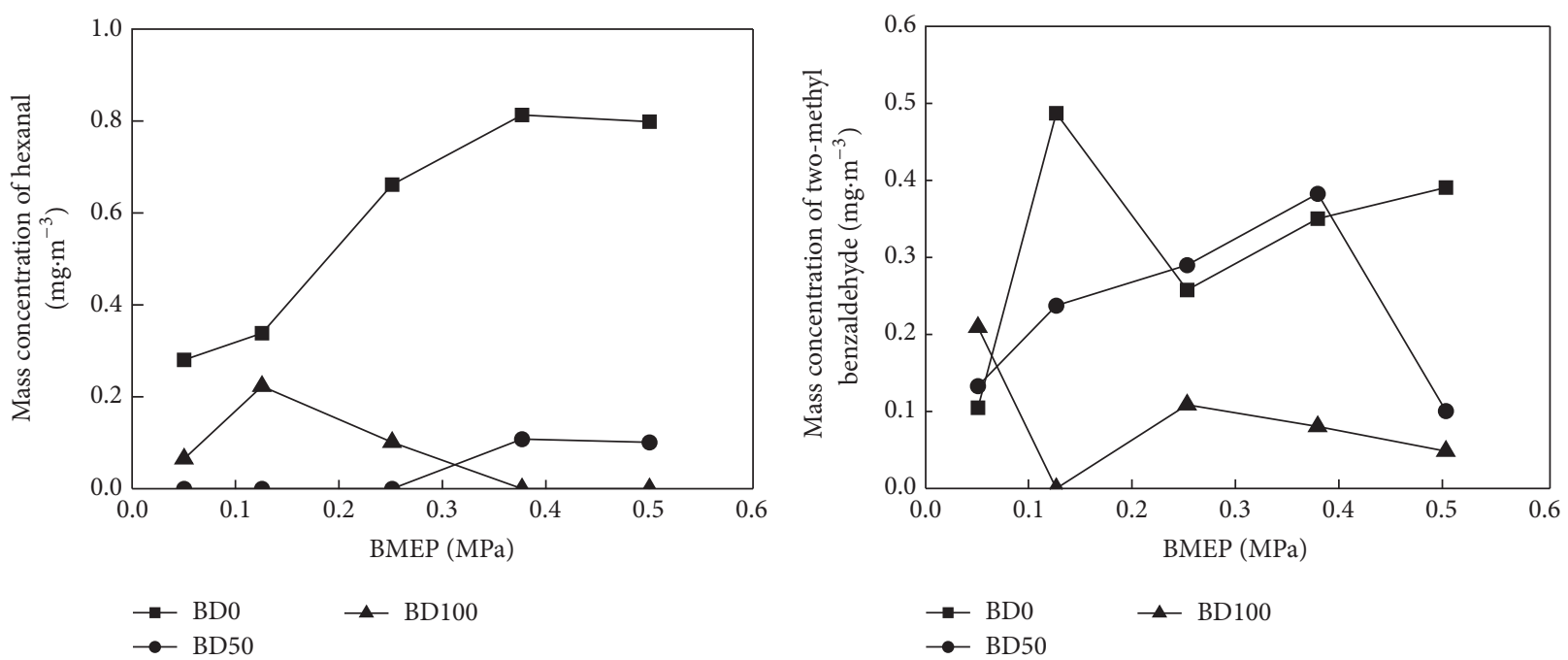

(k) Hexanal

(1) Benzaldehyde

FIGURE 2: Specific carbonyl compounds emission with engine load. 


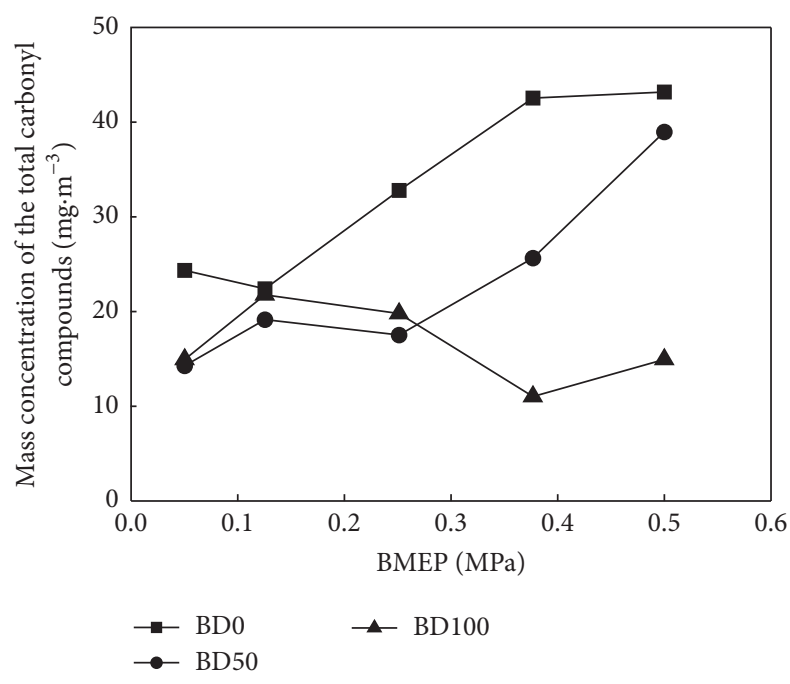

FIGURE 3: Total carbonyl compounds emission with engine load.

propionaldehyde. The formaldehyde accounts for more than $80 \%$ of the total carbonyl pollutants for BD100.

Compared with diesel, biodiesel contains about $11 \%$ oxygen. In biodiesel combustion process, more oxygen can be provided $[15,16]$. The combustion-assistant characteristics of oxygen in biodiesel can promote the fuel combustion and improve the combustion efficiency, conducive to the oxidation of THC, including carbonyls. The diesel engine fueled with biodiesel has a higher combustion temperature and pressure compared with diesel. The retention time of the intermediate products in the high temperature and high pressure region was prolonged, increasing the probability of reoxidation and conversion, which is benefit for the reduction of carbonyl emission. So carbonyl emissions of diesel engine fueled with biodiesel are lower than diesel.

During the diesel premixed combustion stage, the fuel vapor/air mixture is easy to form in the shear boundary layer on the outer edge of the oil beam. When oxidation reaction occurs, the intermediate products such as formaldehyde, $\mathrm{C}_{3}$, $\mathrm{C}_{5}, \mathrm{C}_{7}, \mathrm{CO}$, and $\mathrm{C}_{2} \mathrm{H}_{2}$, are formed $[17,18]$. However, the molecular structure of fuel has a great influence on the type and content of carbonyl pollutants. The main component of biodiesel is methyl ester. Formaldehyde as an important intermediate in the combustion process can be consumed in the subsequent oxidation reaction. In the low temperature chemical reaction stage, the fast isomerization reaction of $\mathrm{RO}_{2}$ occurs in the methyl ester functional group, and the dehydrogenation and decomposition of fuel molecules occur in the high temperature combustion stage $[19,20]$. Therefore, formaldehyde emission is the highest among the carbonyl emissions when diesel engine fueled with biodiesel.

When at low load, the in-cylinder temperature is lower, and the oxidation reaction of carbonyl pollutants is weaker. Therefore, much more aldehydes are generated in the quenching layer of combustion chamber wall, resulting in higher carbonyl emissions. With the increase of engine load, the in-cylinder temperature is increased and the ignition delay period is shortened. High temperature reaction time is increased. Therefore, the probability of reoxidation for carbonyl pollutants is increased, resulting in lower carbonyl emissions.

\section{Simulation on Influencing Factors of Carbonyl Emissions}

As $T, P, \varepsilon, \lambda$, and EGR ratio will also influence the carbonyl compounds emission of diesel engine, we chose CHEMKIN to study the effect of these influencing factors on formaldehyde emission.

In HCCI condition, fuel and air are well mixed in the combustion chamber, and the burning velocity is only affected by chemical kinetics of the fuel oxidation reaction; therefore, the internal combustion engine model was used in this paper. The initial conditions, such as cylinder bore, stroke, and displacement, were referred to the parameters of 186FA diesel engine, and the working condition was the rated condition $(3600 \mathrm{rpm}, 0.50 \mathrm{MPa})$. The mechanism of methyl decanoate $\left(\mathrm{C}_{11} \mathrm{H}_{22} \mathrm{O}_{2}\right)$ and n-heptane $\left(\mathrm{C}_{7} \mathrm{H}_{16}\right)$ were used as the alternative mechanisms of biodiesel and diesel. Methyl decanoate mechanism was the detailed chemical kinetics mechanism containing 3012 substances and 8820 step reactions established by Herbinet et al. [21], and n-heptane mechanism was the detailed chemical kinetics mechanism containing 544 substances and 2446 step reactions established by Curran et al. [22]. In the simulation, the O-D single zone model and Woschni heat transfer model were used.

3.1. Sensitivity Analysis. Sensitivity analysis can be used to analyze the sensitivity of the components, elementary reactions, and reaction conditions to the system response parameters. By sensitivity analysis, we can get the elementary reactions which have great influences on the calculation results and then reveal the derivative process of the substance.

Figure 4 shows the sensitivity analysis results of formaldehyde combustion process in HCCI for biodiesel (methyl decanoate). It can be seen that R2, R6, and R8 have great influence on the formation of formaldehyde; R6 has the function of promoting the formation of formaldehyde. $m d 2 j$ generated by $\mathrm{R} 6$ is an important intermediate product cracked by methyl decanoate molecular, and R6 guarantees that a large amount of active radicals can be produced at low temperature. However, R8 and R2 have the effect of inhibiting the formation of formaldehyde. $\mathrm{R} 2$ can inhibit the cracking reaction of methyl decanoate. ho2 generated by $\mathrm{R} 8$ is a kind of superoxide acid molecule with high activity, which greatly promotes the oxidation and decomposition of formaldehyde at high temperature.

3.2. Intake Temperature. Figure 5(a) shows formaldehyde concentration with different $T . P$ is $0.12 \mathrm{MPa}$, rotation is $3600 \mathrm{rpm}$, and $\varepsilon$ is 19 . It can be seen that the start time of formaldehyde formation reaction is advanced with the increase of $T$. The formation amount of formaldehyde is reduced with the increase of $T$, but it is not obvious when $T$ is high compared to $480 \mathrm{~K}$. In addition, formaldehyde will disappear with the increase of crank angle. 


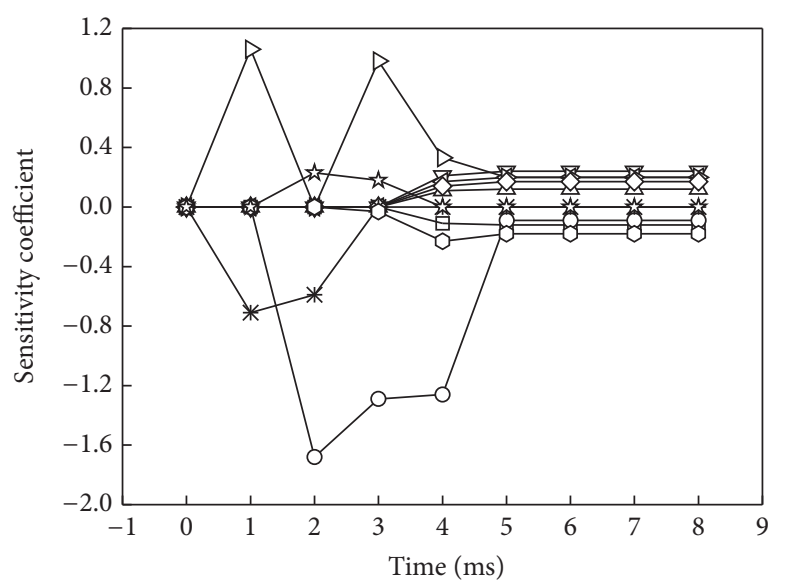

$\rightarrow$ R $1: \mathrm{me} 2 \mathrm{j}+\mathrm{c} 8 \mathrm{~h} 17-1 \Leftrightarrow \mathrm{md} \quad \rightarrow \mathrm{R} 6: \mathrm{ch} 3 \mathrm{o}+\mathrm{c} 8 \mathrm{~h} 17 \mathrm{chco} \Leftrightarrow \mathrm{md} 2 \mathrm{j}$

$\multimap \mathrm{R} 2: \operatorname{ch} 3$ oco $+\mathrm{c} 9 \mathrm{~h} 19-1 \Leftrightarrow$ md $\neg$ R7: $\operatorname{ch} 20+\operatorname{ch} 3 \mathrm{co} \Leftrightarrow$ memj

$\neg-$ R3: $m d+h o 2 \Leftrightarrow m d 2 j+h 2 o 2 \rightarrow$ R $8: m d 2 j+o 2 \Leftrightarrow \operatorname{md} 2 d+h o 2$

$\rightarrow-\mathrm{R} 4: \mathrm{md}+\mathrm{ho} 2 \Leftrightarrow \mathrm{md} 4 \mathrm{j}+\mathrm{h} 2 \mathrm{o} 2 \multimap \mathrm{R} 9: \mathrm{md} 2 \mathrm{j}+\mathrm{o} 2 \Leftrightarrow \mathrm{md} 2 \mathrm{o} 2$

$\neg-\mathrm{R} 5 \mathrm{md}+\mathrm{ho} 2 \Leftrightarrow \mathrm{md} 8 \mathrm{j}+\mathrm{h} 2 \mathrm{o} 2 \multimap$ R10: $\mathrm{memj}+\mathrm{o} 2 \Leftrightarrow \mathrm{memo} 2$

FIGURE 4: Sensitivity analysis of formaldehyde.

In the internal combustion engine model, the combustion process is divided into two stages: low temperature reaction stage and high temperature reaction stage. At lower temperature, the quick isomerization reactions of methyl decanoate are slower, and the generating quantity of $\mathrm{OH}$ radical is reduced. With the increase of $T$, the collision probability between molecules is increased. The increased collision will produce two effects: (1) accelerating the generation of radical in low temperature reaction stage; (2) generating heat to preheat the unburned mixture, which will accelerate the dehydrogenation and decomposition reaction of fuel molecules in high temperature reaction stage. Therefore, higher $T$ is helpful for promoting the decomposition reaction of formaldehyde in the combustion process, resulting in less formaldehyde emission.

3.3. Intake Pressure. Figure 5(b) shows formaldehyde concentration with different pressures. $T$ is $460 \mathrm{~K}$, rotation is $3600 \mathrm{rpm}$, and $\varepsilon$ is 19 . It can be seen that the reaction rate is inversely proportional to the inlet pressure. With the increase of $P$, the start time of formaldehyde formation reaction is advanced, and the final formaldehyde emission is reduced. Since the formation of formaldehyde mainly happened in the low temperature reaction stage, when $P$ is increased, the in-cylinder temperature will be increased, and the quick isomerization reaction of methyl decanoate will be inhabited. Meanwhile, higher temperature will promote the decomposition reaction of formaldehyde in the high temperature reaction stage, resulting in the reduction of formaldehyde.

3.4. Compression Ratio. When $T$ is $460 \mathrm{~K}$ and $P$ is $0.1 \mathrm{MPa}$ and rotation is $3600 \mathrm{rpm}$, formaldehyde concentration with different $\varepsilon$ is shown in Figure 5(c). It can be seen that, with the increase of $\varepsilon$, the start of formaldehyde reaction is advanced. Besides, higher $\varepsilon$ results in faster generation and decomposition of formaldehyde, increasing the final emission of formaldehyde.

The ignition process is closely related to the temperature and cylinder pressure of the mixture during the compression process, and the compression ratio will directly affect the temperature and pressure of mixture in compression stroke. If the compression ratio is increased, both the in-cylinder temperature and pressure will be increased, leading to earlier ignition of the fuel. Therefore, the quick isomerization reaction of methyl decanoate in low temperature reaction stage will accelerate and promote the decomposition reaction of formaldehyde in the high temperature reaction stage.

3.5. Excess Air Coefficient. When $T$ is $460 \mathrm{~K}, P$ is $0.12 \mathrm{Mpa}, \varepsilon$ is 15 , and rotation is $3600 \mathrm{rpm}$, formaldehyde concentration with different $\lambda$ is shown in Figure 5(d). It can be seen that when $\lambda$ is lower than 1.7, the generation rate and the final emission of formaldehyde are increased with the increase of $\lambda$. When $\lambda$ is higher than 1.7, the generation rate of formaldehyde is increased with the increase of $\lambda$.

When diesel engine is at a lower $\lambda$ and higher load, the in-cylinder temperature and pressure are higher, and this will cause an increase in formation reaction rate of formaldehyde. However, the decomposition reaction of formaldehyde has not occurred in the high temperature reaction stage. When $\lambda$ is higher than 1.7, the formation reaction rate of formaldehyde will continue to accelerate, and at the same time, the oxidation decomposition occurs at the initial stage of high temperature reaction stage. In addition, the production rate is lower than the decomposition rate, resulting in a sharp decline in formaldehyde emissions.

3.6. EGR Ratio. In HCCI mode, both higher $\lambda$ and EGR ratio are required for further diluted mixture. When $T$ is $460 \mathrm{~K}, P$ is $0.12 \mathrm{MPa}, \varepsilon$ is 15 , and rotation is $3600 \mathrm{rpm}$, formaldehyde concentration with different EGR ratios is shown in Figure 5(e). As can be seen, with the increase of EGR ratio, the generation amount of formaldehyde is reduced. It is generally recognized that formaldehyde is the intermediate oxidation product of unburned $\mathrm{HC}$ in the cylinder and exhaust system. The residual gas with high temperature promotes the evaporation of fuel and improves the mixing of oil and air, leading to more sufficient combustion. Therefore, the formaldehyde is reduced with the increase of EGR ratio.

\section{Measures of Reducing Formaldehyde}

4.1. Air Pretreatment. Air pretreatment is a kind of preprocessing technology for reducing emissions of diesel engine. For example, the dilution of air can reduce the oxygen content in the air and reduce $\mathrm{NO}_{X}$ effectively. Air dilution ratio is the proportion of $\mathrm{O}_{2}$ and $\mathrm{N}_{2}$ in the air. Here the dilution factor $D$ is defined as

$$
D=\frac{X_{\mathrm{O}_{2}}}{X_{\mathrm{O}_{2}}+X_{\mathrm{N}_{2}}},
$$

in which, $X$ is molar concentration. 


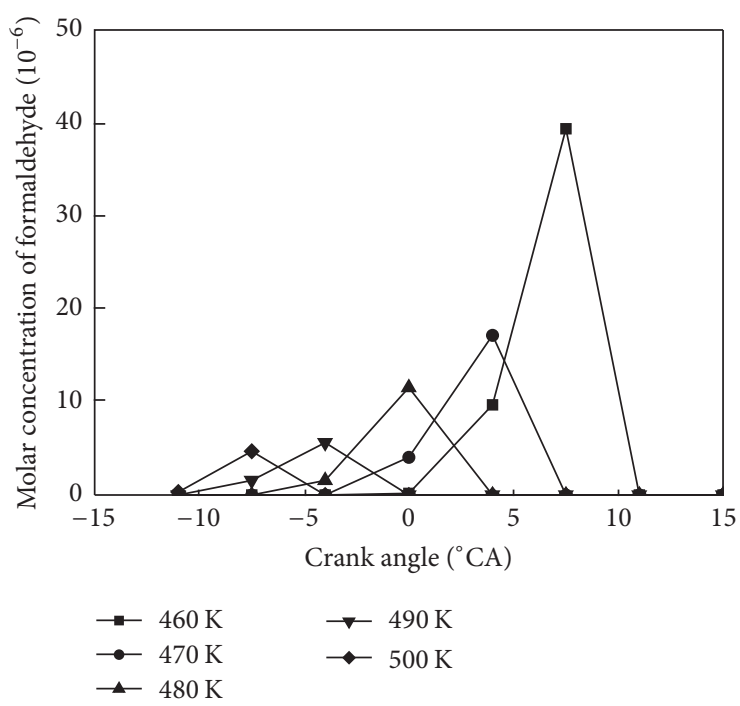

(a) Intake temperature

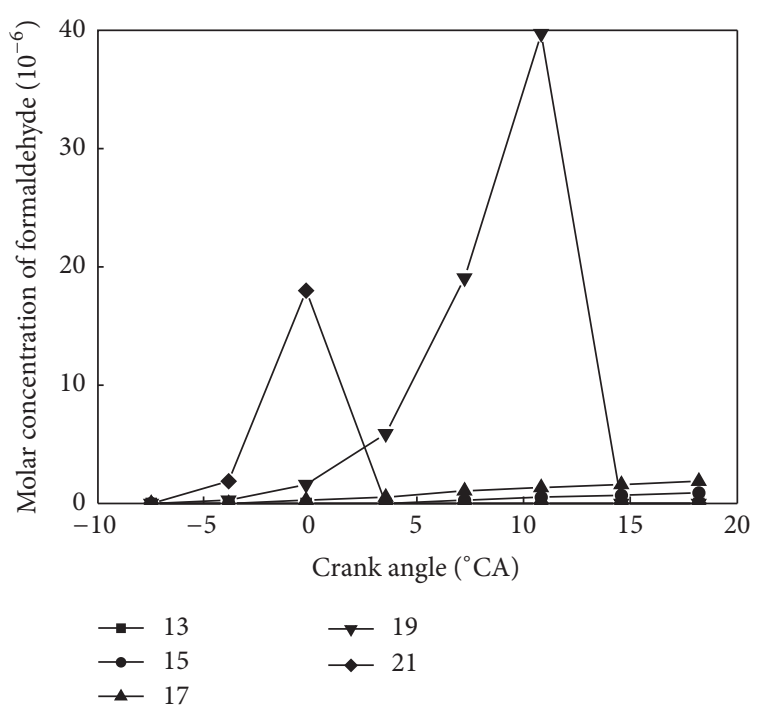

(c) Compression ratio

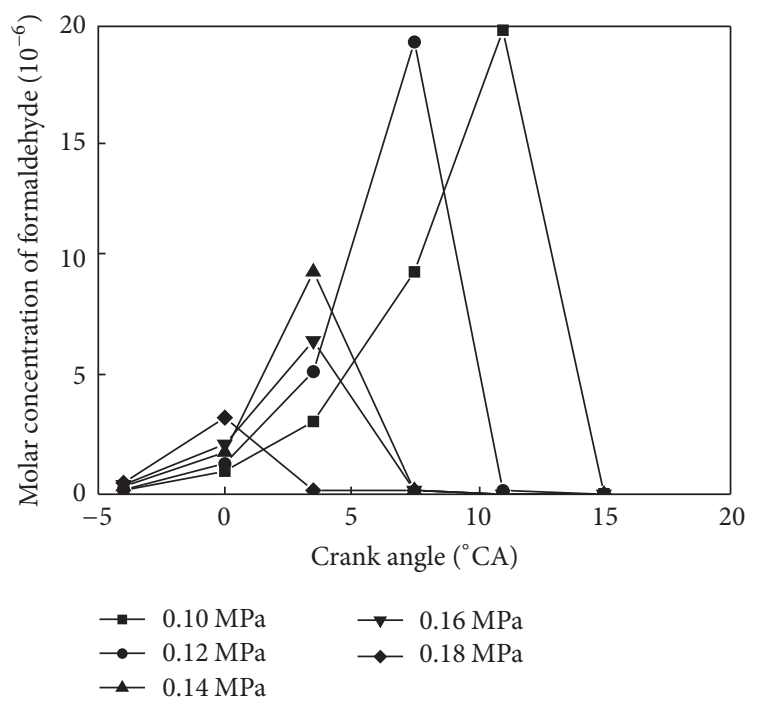

(b) Intake pressure

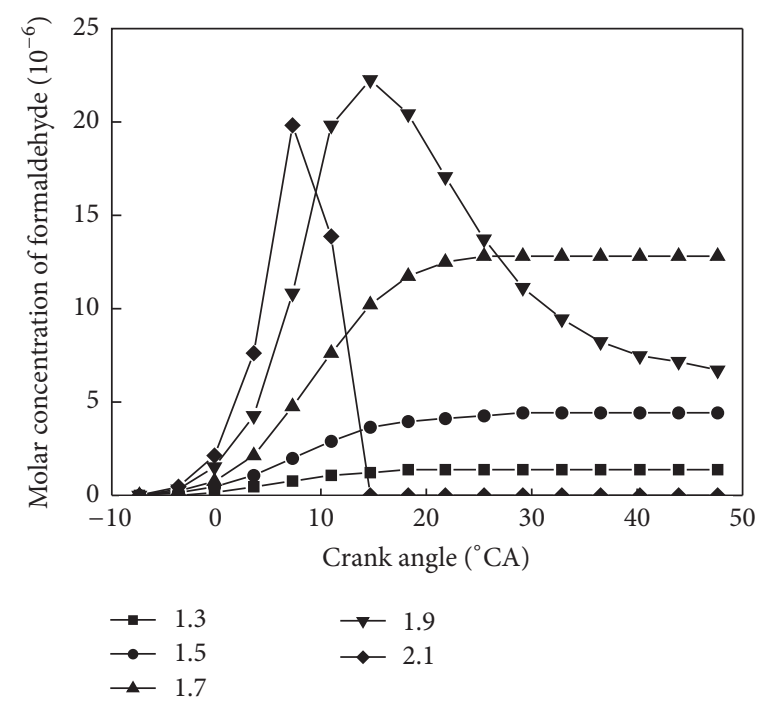

(d) Excess air coefficient

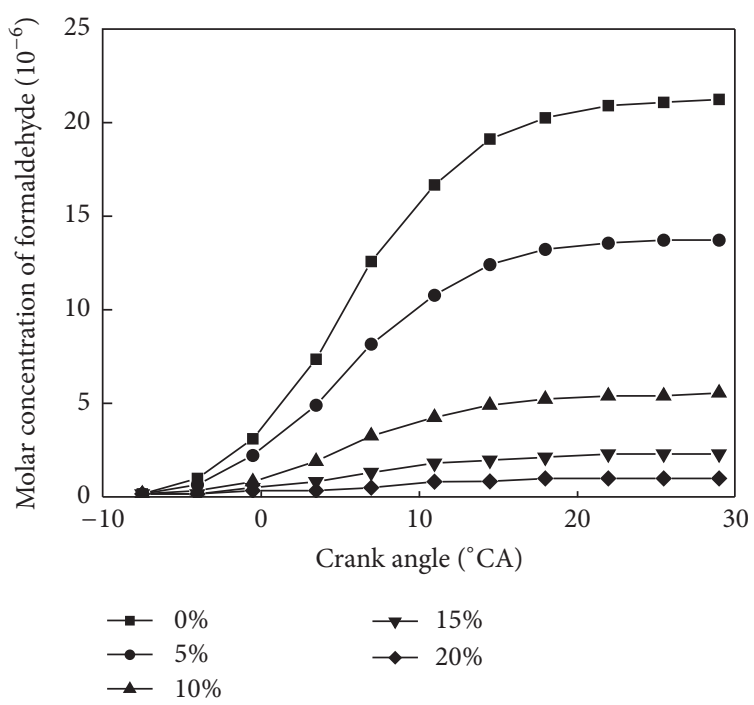

(e) EGR ratio

FIGURE 5: Influence of temperature, pressure, compression ratio, excess air coefficient, and EGR ratio on formaldehyde emission. 


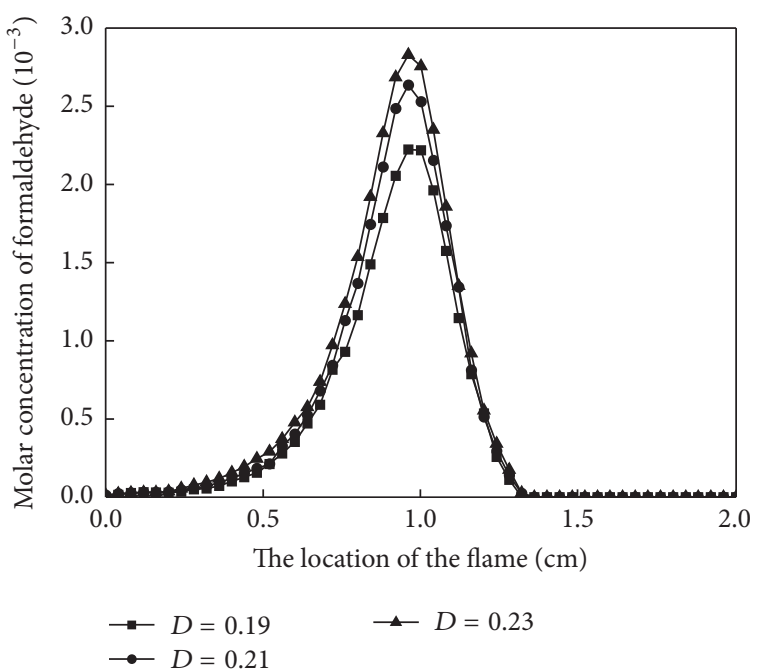

(a) Diesel

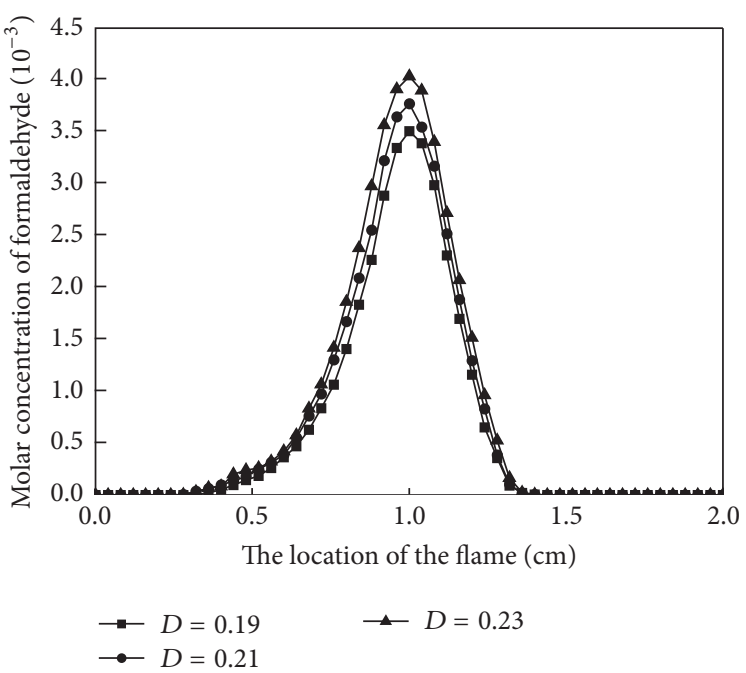

(b) Biodiesel

FIGURE 6: Influence of air dilution ratio on formaldehyde emission for diesel and biodiesel.

Figure 5(a) is the relationship between formaldehyde concentration in diesel premixed flame and air dilution ratios. $D=0.21$ is the dilution factor in the common condition. It can be seen, with the decrease of $D$, that the formaldehyde concentration in the premixed flame is reduced. When $D$ is reduced from 0.23 to 0.19 , the peak concentration is reduced by about $21 \%$. It is obvious that the dilution of air reduces the formaldehyde emission effectively.

Figure $6(\mathrm{~b})$ is the relationship between formaldehyde concentration in biodiesel premixed flame and air dilution ratios. It can be seen that the peak of formaldehyde concentration in the premixed flame is reduced with the decrease of air dilution ratio. When the dilution factor is reduced from 0.23 to 0.19 , the peak of formaldehyde concentration is reduced about $13 \%$. With the reduction of air dilution ratio, the oxygen concentration in the combustion chamber is reduced. Since biodiesel is a kind of oxygenated fuel, oxygen in biodiesel is helpful for combustion. Therefore, the air dilution ratio show less effect on the reduction of formaldehyde concentration in biodiesel premixed flame.

4.2. Fuel Pretreatment. The fuel pretreatment technology is aimed at improving the quality of fuel and reducing emissions by fuel reorganization or additive addition before injecting into the cylinder. Generally, adding hydrogen, carbon monoxide or methane are good pretreatment methods to reduce diesel engine emissions [23-25].

4.2.1. The Addition of Hydrogen. The addition of hydrogen into the fuel can improve the lean combustion stability and expand the ignition limit of the combustible mixture, reducing fuel consumption and emissions. Figure 7 shows the effect of hydrogen addition on formaldehyde concentration in the biodiesel premixed flame. As can be seen, the formaldehyde concentration peak is reduced with the increase of hydrogen amount. When the addition amount of hydrogen is increased

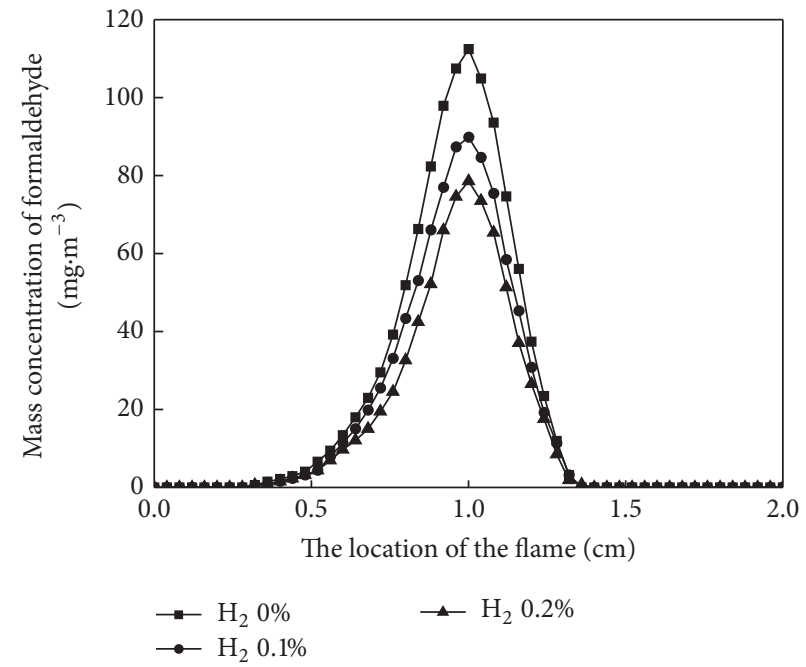

FIGURE 7: Influence of the addition of $\mathrm{H}_{2}$ on formaldehyde emission for biodiesel.

from $0 \%$ to $0.2 \%$, the formaldehyde concentration peak is reduced by about $30 \%$.

4.2.2. The Addition of CO. Figure 8 shows the effect of $\mathrm{CO}$ addition on formaldehyde concentration in the biodiesel premixed flame. As can be seen, the formaldehyde concentration peak is reduced with the increase of $\mathrm{CO}$ amount. When the addition amount of $\mathrm{CO}$ is increased from $0 \%$ to $0.2 \%$, the formaldehyde concentration peak is reduced by about $23 \%$.

4.2.3. The Addition of Methane. Study shows that diesel dissolving methane has longer ignition delay period and lower premixed heat release rate peak; meanwhile, $\mathrm{NO}_{X}$ and soot are reduced [24]. Figure 9 shows the effect of methane 


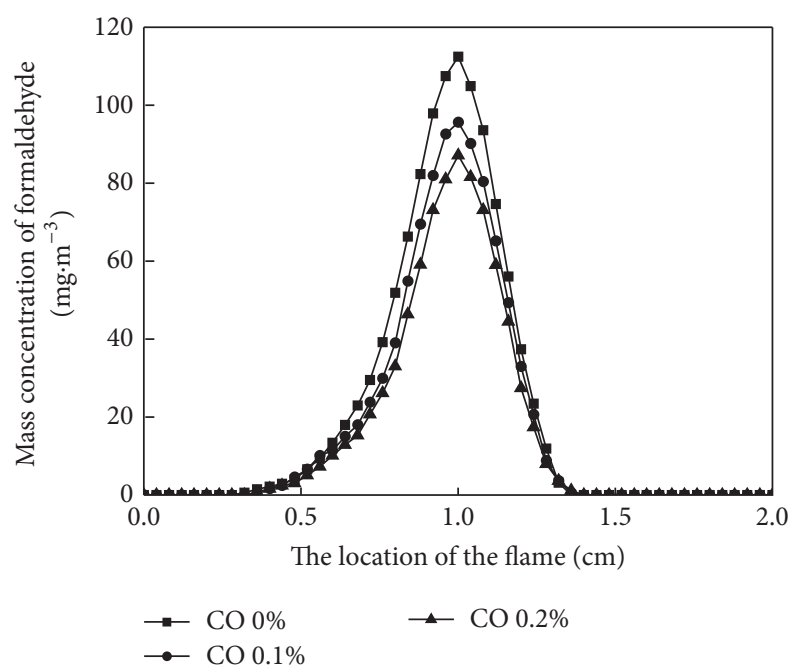

FIGURE 8: Influence of the addition of $\mathrm{CO}$ on formaldehyde emission for biodiesel.

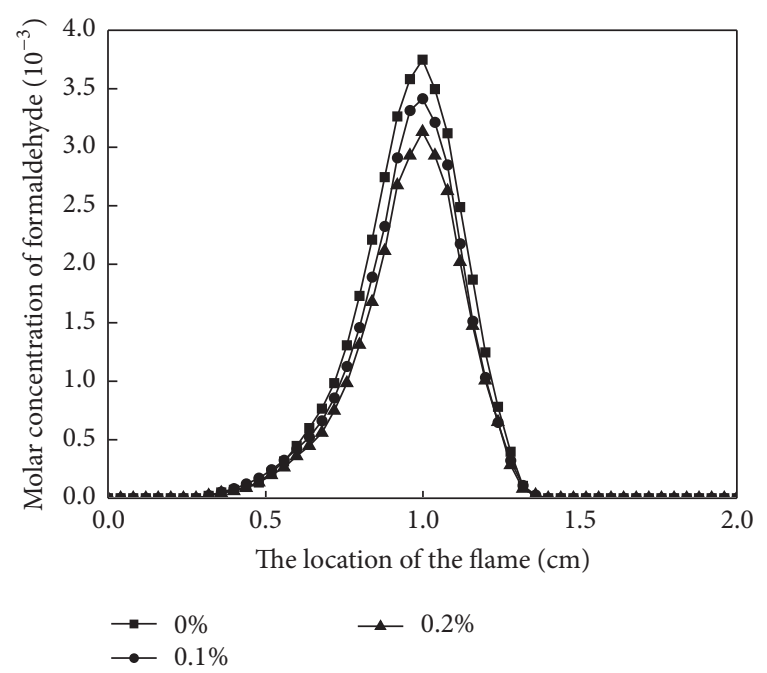

FIGURE 9: Influence of the addition of $\mathrm{CH}_{4}$ on formaldehyde emission for biodiesel.

addition on formaldehyde concentration in the biodiesel premixed flame. As can be seen, the formaldehyde concentration peak is reduced with the increase of methane amount. When the addition amount of methane is increased from $0 \%$ to $0.2 \%$, the formaldehyde concentration peak is reduced by about $16 \%$.

The analysis on measures of formaldehyde reduction shows that both air pretreatment and fuel pretreatment can reduce formaldehyde concentration of diesel and biodiesel. The air pretreatment shows better effect on reducing formaldehyde of diesel than biodiesel. The biodiesel pretreatment by adding hydrogen, $\mathrm{CO}$, or methane can improve the mixing of oil and gas and increase the flame temperature and adiabatic burning velocity, resulting in the reduction of formaldehyde. Among the three fuel pretreatment measures, the addition of hydrogen has the best on reducing formaldehyde of biodiesel.

\section{Conclusion}

Carbonyl pollutants of diesel engine fueled with biodiesel and biodiesel/diesel blend were measured by solvent extraction and HPLC technology. The effects of biodiesel blending ratio and diesel engine conditions on 13 kinds of carbonyl pollutants were studied. According to the chemical reaction kinetic analysis of diesel and biodiesel, the effects of $T, P$, $\varepsilon, \lambda$, and EGR ratio on formaldehyde concentration were investigated. In addition, measures of reducing formaldehyde were simulated and analyzed. Carbonyl pollutants of diesel engine fueled with BD0, BD50, and BD100 are mainly aldehyde and ketone compounds with 1-3 carbon atoms, such as formaldehyde, acetaldehyde, acrolein, and propionaldehyde. The formaldehyde content is the highest, higher than $80 \%$ of the total carbonyl pollutants for BD100. Within the entire engine load, the total carbonyl pollutants concentration for $\mathrm{BD} 0$ is the higher than BD50 and BD100. The chemical reaction kinetic analysis shows that the formaldehyde concentration peak is reduced with the increase of $T, P$, and EGR ratio and increased with the increase of $\varepsilon$. The formaldehyde concentration in the premixed flame of diesel can be reduced by air pretreatment effectively, especially the addition of hydrogen, while air pretreatment shows less effect on reducing formaldehyde concentration of biodiesel.

\section{Nomenclature}

HPLC: High performance liquid chromatography

B5: $\quad 5 \%$ biodiesel in diesel

$T: \quad$ Intake temperature $(\mathrm{K})$

THC: Total hydrocarbon

$P: \quad$ Intake pressure $(\mathrm{MPa})$

DOC: Diesel oxidation catalyst

EGR: Exhaust gas recirculation

BMEP: Break mean effective pressure

$\varepsilon: \quad$ Compression ratio

UV: Ultraviolet

$\lambda: \quad$ Excess air coefficient

$X: \quad$ Average value

BD100: Biodiesel

RSD: Relative standard deviation.

\section{Competing Interests}

The authors declare that there is no conflict of interests regarding the publication of this paper.

\section{Acknowledgments}

This study was financially supported by the National Natural Science Foundation of China under Grant no. 51376083.

\section{References}

[1] Z. Wang, G. Xu, H. Huang, L. Wang, H. Zha, and J. Ma, "Reliability test of diesel engine fueled with biodiesel," Nongye Gongcheng Xuebao/Transactions of the Chinese Society of Agricultural Engineering, vol. 25, no. 11, pp. 169-172, 2009. 
[2] O. Özener, L. Yüksek, A. T. Ergenç, and M. Özkan, "Effects of soybean biodiesel on a DI diesel engine performance, emission and combustion characteristics," Fuel, vol. 115, pp. 875-883, 2014.

[3] R. N. Li, Z. Wang, M. D. Li, G. J. Xu, G. P. Mao, and X. Z. Wang, "Study on effect of peroxide properties for biodiesel and emissions," Acta Armamentar II, vol. 33, no. 12, pp. 1545-1548, 2012.

[4] X. Wang, Y. S. Ge, L. X. Yu, and X. Y. Feng, "Comparison of combustion characteristics and brake thermal efficiency of a heavy-duty diesel engine fueled with diesel and biodiesel at high altitude," Fuel, vol. 107, pp. 852-858, 2013.

[5] M. Lapuerta, O. Armas, and J. Rodríguez-Fernández, "Effect of biodiesel fuels on diesel engine emissions," Progress in Energy and Combustion Science, vol. 34, no. 2, pp. 198-223, 2008.

[6] P. Singh, Varun, and S. R. Chauhan, "Carbonyl and aromatic hydrocarbon emissions from diesel engine exhaust using different feedstock: a review," Renewable \& Sustainable Energy Reviews, vol. 63, pp. 269-291, 2016.

[7] K. F. Ho, S. Sai Hang Ho, Y. Cheng, S. C. Lee, and J. Zhen $\mathrm{Yu}$, "Real-world emission factors of fifteen carbonyl compounds measured in a Hong Kong tunnel," Atmospheric Environment, vol. 41, no. 8, pp. 1747-1758, 2007.

[8] A. Lance, E. D. Wallace, T. Y. D. Hartwell, C. M. Sparacino, L. S. Sheldon, and H. Zelon, "Personal exposures, indoor-outdoor relationships, and breath levels of toxic air pollutants measured for 355 persons in New Jersey," Atmospheric Environment, vol. 19, no. 10, pp. 1651-1661, 1985.

[9] C.-S. Yuan, Y.-C. Lin, C.-H. Tsai, C.-C. Wu, and Y.-S. Lin, "Reducing carbonyl emissions from a heavy-duty diesel engine at US transient cycle test by use of paraffinic/biodiesel blends," Atmospheric Environment, vol. 43, no. 39, pp. 6175-6181, 2009.

[10] M. Chai, M. Lu, F. Liang, A. Tzillah, N. Dendramis, and L. Watson, "The use of biodiesel blends on a non-road generator and its impacts on ozone formation potentials based on carbonyl emissions," Environmental Pollution, vol. 178, pp. 159-165, 2013.

[11] C. He, Y. Ge, J. Tan et al., "Comparison of carbonyl compounds emissions from diesel engine fueled with biodiesel and diesel," Atmospheric Environment, vol. 43, no. 24, pp. 3657-3661, 2009.

[12] R. Ballesteros, J. Guillén-Flores, and J. D. Martínez, "Carbonyl emission and toxicity profile of diesel blends with an animal-fat biodiesel and a tire pyrolysis liquid fuel," Chemosphere, vol. 96, pp. 155-166, 2014.

[13] Z. H. Zhang, C. S. Cheung, T. L. Chan, and C. D. Yao, "Experimental investigation of regulated and unregulated emissions from a diesel engine fueled with Euro V diesel fuel and fumigation methanol," Atmospheric Environment, vol. 44, no. 8, pp. 1054-1061, 2010.

[14] K. Drobot, W. K. Cheng, F. H. Trinker et al., "Hydrocarbon oxidation in the exhaust port and runner of a spark ignition engine," Combustion and Flame, vol. 99, no. 2, pp. 422-430, 1994.

[15] J. P. Szybist, J. Song, M. Alam, and A. L. Boehman, "Biodiesel combustion, emissions and emission control," Fuel Processing Technology, vol. 88, no. 7, pp. 679-691, 2007.

[16] O. Özener, L. Yüksek, A. T. Ergenç, and M. Özkan, "Effects of soybean biodiesel on a DI diesel engine performance, emission and combustion characteristics," Fuel, vol. 115, pp. 875-883, 2014.

[17] W. Zhang, C.-L. Song, F.-C. Li et al., "Study on carbonyl emissions from an engine fueled with ethanol/diesel blends," Transactions of CSICE, vol. 26, no. 3, pp. 238-242, 2008.
[18] C.-D. Yao, H.-M. Peng, Y.-T. Liu, and S. Li, "Formaldehyde emission characteristic from diesel/methanol compound combustion engine," Transactions of CSICE, vol. 26, no. 3, pp. 233237, 2008.

[19] L. Zhu, C. S. Cheung, W. G. Zhang, J. H. Fang, and Z. Huang, "Effects of ethanol-biodiesel blends and diesel oxidation catalyst (DOC) on particulate and unregulated emissions," Fuel, vol. 113, pp. 690-696, 2013.

[20] M. C. Rodrigues, L. L. N. Guarieiro, M. P. Cardoso, L. S. Carvalho, G. O. da Rocha, and J. B. de Andrade, "Acetaldehyde and formaldehyde concentrations from sites impacted by heavy-duty diesel vehicles and their correlation with the fuel composition: diesel and diesel/biodiesel blends," Fuel, vol. 92, no. 1, pp. 258-263, 2012.

[21] O. Herbinet, W. J. Pitz, and C. K. Westbrook, "Detailed chemical kinetic oxidation mechanism for a biodiesel surrogate," Combustion and Flame, vol. 154, no. 3, pp. 507-528, 2008.

[22] H. J. Curran, P. Gaffuri, W. J. Pitz, and C. K. Westbrook, "A comprehensive modeling study of $n$-heptane oxidation," Combustion and Flame, vol. 114, no. 1-2, pp. 149-177, 1998.

[23] J.-Y. Ren, W. Qin, F. N. Egolfopoulos, and T. T. Tsotsis, "Strainrate effects on hydrogen-enhanced lean premixed combustion," Combustion and Flame, vol. 124, no. 4, pp. 717-720, 2001.

[24] F. H. V. Coppens, J. De Ruyck, and A. A. Konnov, "Effects of hydrogen enrichment on adiabatic burning velocity and NO formation in methane + air flames," Experimental Thermal and Fluid Science, vol. 31, no. 5, pp. 437-444, 2007.

[25] Y. Jiang, R. Qiu, and C. L. Song, "Numerical predictions of hydrogen-enriched premixed methane/air flames," Journal of Combustion Science and Technology, vol. 15, pp. 196-202, 2009. 


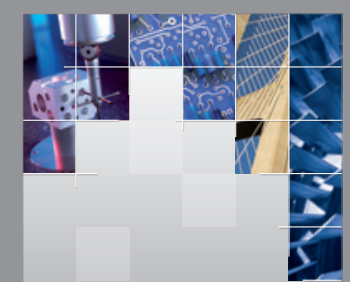

\section{Enfincering}
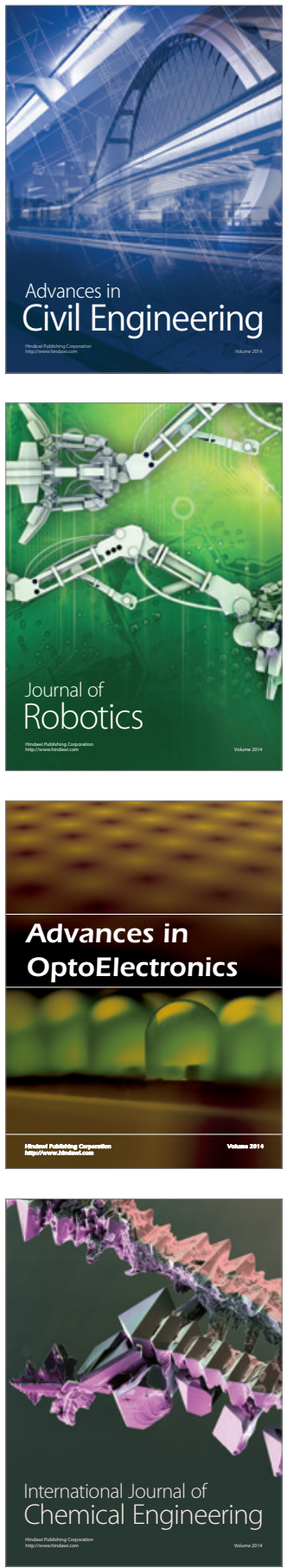

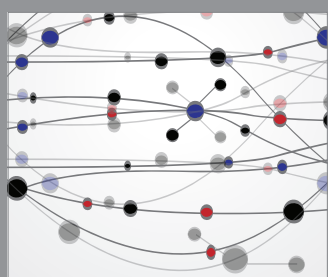

The Scientific World Journal

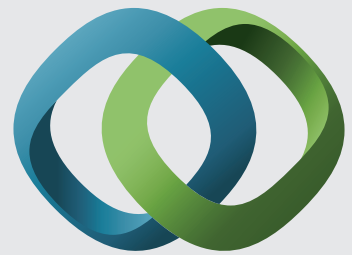

\section{Hindawi}

Submit your manuscripts at

https://www.hindawi.com
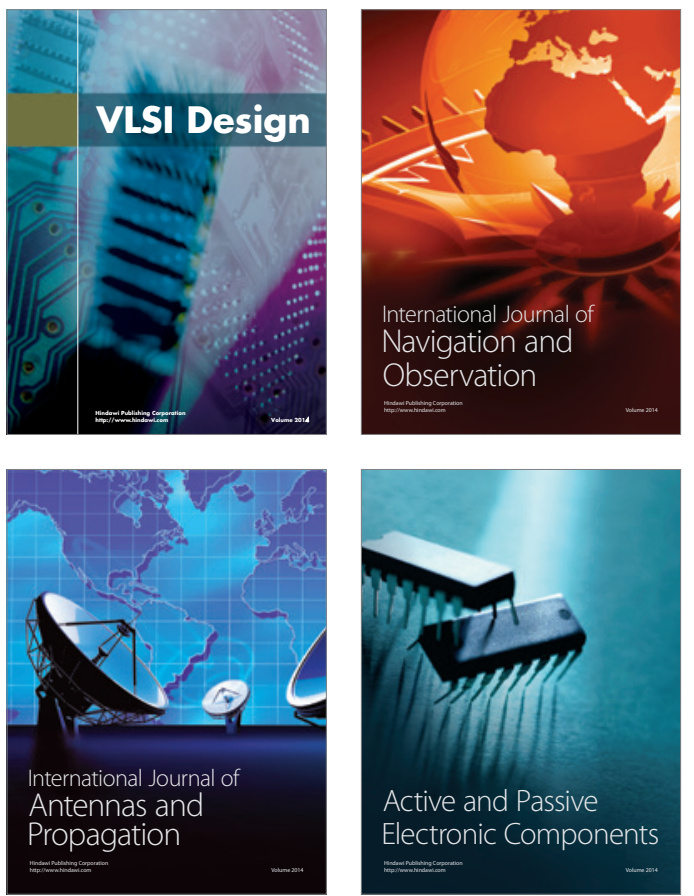
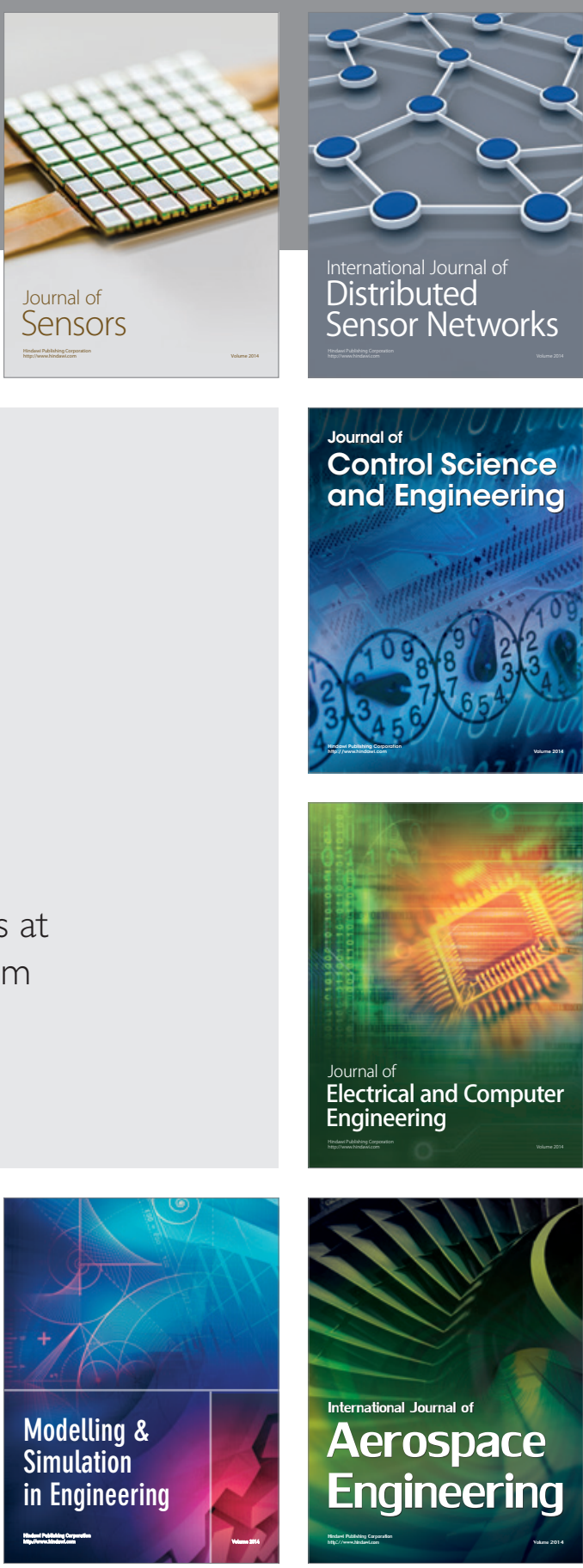

International Journal of

Distributed

Sensor Networks

$-$

Joumal of

Control Science

and Engineering
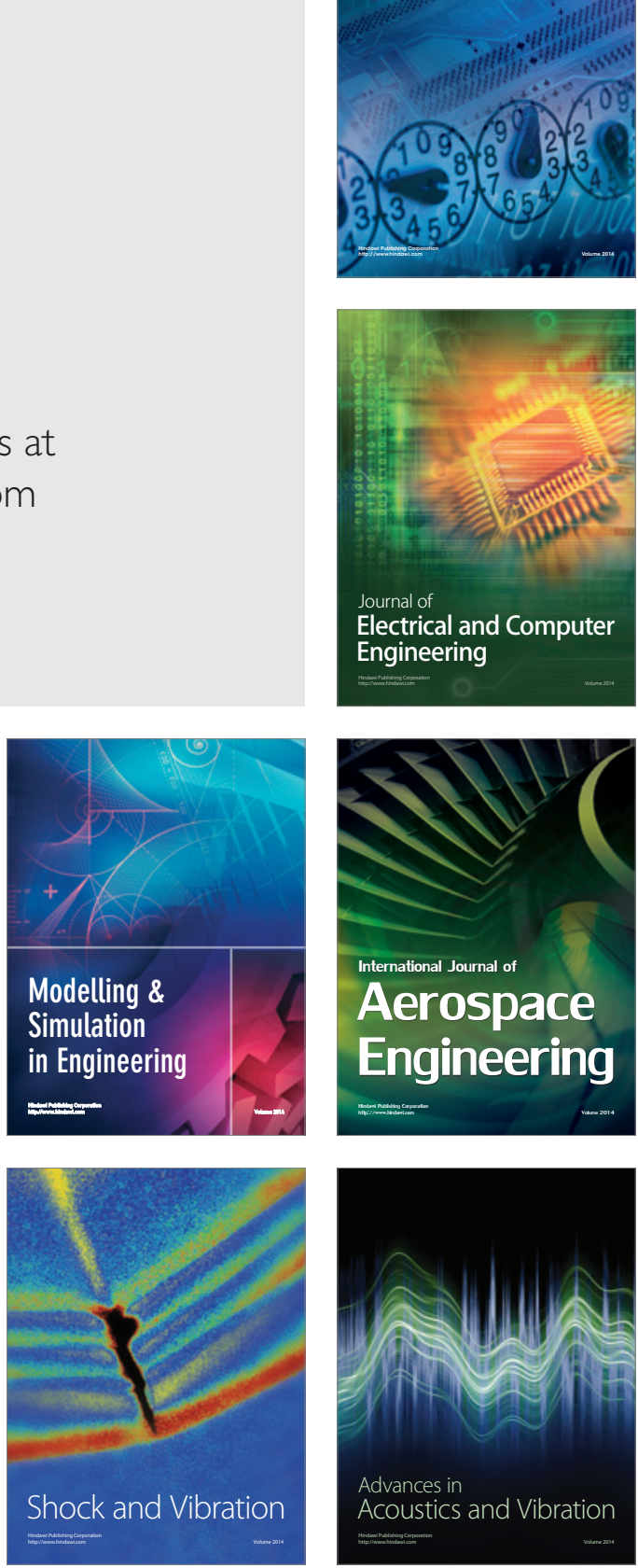